\title{
A STUDY OF WRITTEN ENGLISH IN NEPAL
}

\author{
Ram Ekwal Singh \\ Associate Professor, Department of English Education, Kirtipur, T. U. \\ Corresponding author: resingh@outlook.com
}

\begin{abstract}
People in Nepal speak different languages. English is taught as a compulsory subject up to bachelor level. Writing skill in compulsory English occupies $40 \%$ weightage in class XI syllabus. This research was conducted with the main purposes of analysing the writing tasks and writing serves various purposes in a person's everyday life. Its role is vital for upgrading students and job placement. It has been prescribed in English textbooks for higher secondary level across four subject streams and finding out the English teaching learning processes in the development of writing skills.
\end{abstract}

The study had been delimited to the Kathmandu Valley. The sample comprised Class XI students. Mixed methods were utilized for gathering data such as questionnaire for students, test, students' interview, teachers' opinionnaire, teachers' interview and class observation. All the higher secondary school teachers of English of the sample schools and 25 students of four streams were the respondents. The data was analysed using the Statistical Package for the Social Sciences (SPSS) version 16 and the t-test.

The nature of exercises related to writing in textbooks of Class XI is almost similar, sequential and aims at developing creative writing. Science students performed the best of all on the test followed by Management, Arts and Education students. Almost all the informants expressed that writing grammatically correct sentences is of top most importance. Most of the teachers used process methodology in teaching writing. All informants interviewed expressed writing as a vital skill but it lacks separate classes.

Keywords: writing task - class observation - streams - creative writing - process methodology 


\section{INTRODUCTION}

Nepal is a multilingual, multi-ethnic and multi-religious country where people belong to different ethnic groups, observe different religions and speak different languages. Acharya (1991 as cited in Awasthi, 1995, p.2) divides these languages into four languages families, just as the case in India, i.e. Indo-Aryan (IA), Tibeto-Burman (TB), Austro-Asiatic (AA), and Dravidian (D).

The kind of writing advocated through initiatives like the National Writing Project has dwindled, and writing in English classrooms now is heavily teacher directed, highly structured, assessment objective-driven, leaving little space for pupil choice. Creative writing is marginalised; real audiences are illusory (Gibbons 2019).

Evidence-based practices for writing instruction include, for example, teaching students strategies for planning, revising, and editing their compositions and having students use word processing as a primary tool for writing (Graham \& Perin 2007a as cited in Coelho 2020). From the school medium point of view Nepal has two types of schools- Nepali medium schools and English medium schools but in both of these types of schools teaching of English is compulsory.

We learned to speak our first language at home without systematic instruction, whereas most of us had to be taught in school how to write the same language. Even many adult native speakers of a language find writing difficult (Raimes 1985).

Although all human beings grow up speaking their first language (and sometimes their second or third) as a matter of course, writing has to be taught. Spoken language is acquired by a child naturally as a result of being exposed to it, whereas the ability to write has to be consciously learned.

Process discourse refers to both mental processes that constitute the writing act and practical processes of producing a written product (i.e., planning, drafting, revising). Within this discourse, people get better at the processes of writing by practicing them (Bomer, Land, Rubin \& Dike 2019).

\section{OBJECTIVES OF THE STUDY}

The objectives for the study were: 
I. To analyse the writing tasks prescribed in the Magic of Words for higher secondary level

II. To compare learners' writing skill in English across four subject streams particularly analysing the errors committed by them, and

III. To find out the teaching learning processes involved specially in the development of English writing skills.

\section{SIGNIFICANCE OF THE STUDY}

First, it will be useful to the practising teachers who can benefit themselves with the modifications and adjustments suggested for increasing the effectiveness of teaching writing. They may benefit from the methods suggested. Bacon (1989) rightly said, 'Reading makes a full man, conference a ready man, and writing an exact man' (as cited in Nirmala 2008, p. 18).

Secondly, the curriculum planners can get an insight from the findings of the present research and utilize them in designing future curricula.

Thirdly, it may provide English textbook writers some guidelines while producing materials for various levels of education at the school stage.

Last, Higher Secondary Education Board, Nepal may find the research findings and recommendations helpful in designing its course of future (English) curriculum and prescribing textbook materials. It also has implication for conducting examination and designing proper evaluation schemes.

\section{Delimitations of the Study}

I. The study was done in the urban areas of Nepal, the Kathmandu Valley.

II. The sample group comprised class XI students.

\section{REVIEW OF RELATED LITERATURE}

The review of related literature helps the researcher to bring clarity and focus to the research problem, provides input for improving the methodology and broadens the knowledge base of the researcher in the research area. 
Limbu (2020) carried out research on "Techniques used for providing feedback on students' writing." The objectives of her study were to examine teachers' practice of providing feedback on students' writing, to identify the techniques used by teachers to correct error in developing writing skill, and to suggest some pedagogical implications. The population of her study was all the basic level English teachers of Sunsari district. The sample of her study included two teachers from institutional school of Sunsari district. They were selected by using purposive non-random sampling strategy. The tools used were classroom observation form, semistructured interview and field notes. The main findings of her research were the teachers believed on power of feedback and provided frequent feedback on students' writing, they marked errors and corrected them comprehensively on students' writing, and their techniques to correct error and improve or strengthen writing, finding out error, correcting the erroneous expressions or forms and providing sample writing. She concluded that teachers should use different ways of providing feedback to make teaching writing more effective.

Pokharel (2019) conducted research entitled "Students' perception on the use of ICT in developing English Language writing skills. The objectives of her study were to find out students' perceptions towards the use of ICT in learning English language writing, to identify the commonly used ICT tools in English language writing, and to suggest some pedagogical implications on the basis of the findings of the study. All the students of Master's level from Department of English Education were population of her study. The sample consisted of thirty students of Faculty of Education. They were selected by using Purposive non-random sampling strategy. Open-ended and close-ended questions were used for data collection. She found that $100 \%$ students of Master's level had access and used computer, Internet and mobile learning as a tool in developing English language, $93.5 \%$ respondents viewed that they email and Internet to share and download file, documents and software in developing English language writing, and teachers should use ICT tools while teaching English language Writing Skill. She concluded that almost all teachers and students should have access and knowledge how to use it to bring advancement in education and learning English language writing.

Bhatta (2018) carried out research on "Inquiry based learning for developing writing skill" with objectives to explore and analyze the role of inquiry based approach for developing writing skill and to suggest 
some pedagogical implications of inquiry-based learning. All grade eleven students of Nepalaya Higher Secondary School were the population of the study and thirty of them were the sample selected randomly. Test items such as writing an essay, biography, about historical places were used to collect data. His main finding was that the average score in pre-test was 16.43 (54.74\%), in the progress test it was $19.9(66.33 \%)$ and in the post test it was $24(82.44 \%)$ which showed the continuous progression in students writing He concluded that inquiry had better impact on teaching writing skill and if teachers adopted various students centred and it would change students' writing skill.

Harmer (2006) in "How to Teach Writing" stresses upon the process of writing. Writing process has four main elements planning - draftingediting -final draft. Though there are differences between speaking and writing, yet there are also occasions when speaking and writing look very much the same. Writing needs to be cohesive and coherent to be truly accessible. People use different registers in writing depending on different topics and on the tone they wish to adopt for their intended audience, then students should also be made aware of how this works in English because it helps them to choose language proficiency. Writing has always secured a part of the syllabus in teaching of English and the importance to it differs from teaching situation to teaching situation. It has always been used as a means of reinforcing language that has been taught. It can be used as an integral part of a larger activity where the focus is on language practice, acting out, or speaking. Teaching writing for writing is to help students to become better writers and to learn how to write in various genres using different registers. Writing has its 'mechanical' components which include handwriting, spelling, punctuation, and the construction of well-formed sentences, paragraphs, and texts. They are called the nuts and bolts of the writing skill. Teachers should allow students to enjoy their writing, read and see each other's work, promote them to read out what they have done. Correcting is the stage at which something is not right is indicated. Students' written performance is corrected on the issues such as syntax (word order), concord (grammatical agreement between subjects and verbs), collocation (words which live together), or word choice.

Hairston and Keene (2004) in "Successful Writing" stress that one should start writing by drafting a strong introduction that forecasts the central idea and making notes about the main points. Then notes should be organized in some kind of coherent order and a pattern of presentation 


\section{A STUDY OF WRITTEN ENGLISH IN NEPAL}

should be chosen: possibilities are comparison and contrast, assertion and support, cause and effect, or chronological order. The book also suggests seven precepts that apply to writing:

I. If the assignment permits you to choose your topic, write on a subject that interests you even if it will require a fair amount of work.

II. Don't overstate your case.

III. Support your claims.

IV. Argue logically and avoid highly emotional language.

V. Choose a title that accurately reflects your content.

VI. Cite your sources, either formally or informally.

VII. Make your work look good.

When one writes, one should think more about communicating than about following rules. One does not need special talent to become a good writer. One writes well because one is disciplined, because one works hard at their craft, and because one has developed a set of practices that enables one to turn out good work consistently.

It is a fact that the hardest part of a writing project is getting down the first sentence. Just put down something and start writing- the rest will begin to come. Clarity is one the first quality of good writing. The first rule for holding the readers is to capture their interest. Some more strategies are to choose a good title, write a strong lead, keep your writing tight and unified, keep sentences and paragraphs to a reasonable length, chunk your writing into manageable units, avoid antagonizing your readers, make your writing look good, use figurative and connotative language sparingly, and avoid stereotypes and offensive labelling.

Paragraphs should be created in such a way that they make life easier for your readers. Most good writers see revision as an essential stage of their writing and plan on revising virtually everything they write. Professional writers edit their writing carefully to make a good impression on their readers.

All the reviewed literature indicates that writing is essential for both first language and foreign language learners which can be developed with 
teachers' instruction and correction with explicit and implicit techniques of correction. It is a highly demanded skill everywhere.

\section{METHODOLOGY}

There have been a lot of changes in the areas of research in social sciences over the last couple of decades. For example, the traditional tool, questionnaire survey has been considered as time consuming, costly and ineffective (Chamber, 1983 as cited in Dahal 2011).

In this type of survey due to errors the question of reliability also arises. Hence, many researchers now-a-days use both qualitative and quantitative techniques and tools simultaneously for quality data and information.

Mixed methods were utilized for gathering data and questionnaire for class XI 25 English and 25 Nepali medium students, test, students'/ teachers' interview, teachers' opinionnaire, and class observation were used as tools. Apart from ticking the checklists, the researcher gave attention to opening procedures, closing procedures, use of voice, eye contact, interaction with students (Begum 2009). All the teachers of English of the sample schools and 50 students of four streams were the sample. The data was analysed using the Statistical Package for the Social Sciences (SPSS) version 16. Mean, median, standard deviation, percent, standard errors of mean, the t- test, and Post Hoc Tukey HSD test were used to analyse the data.

Students we are given three questions to write a short paragraph, a short story and a short essay. Each script was graded with A, B, C, D, and E on the basis of five set parameters i.e. coherence, fluency, range of vocabularynew words- use of words in context, grammatical correctness and creativity and thoroughly examined both in terms of what the students could do and what they failed to. The failures which included omission, redundancy, discrepancy or weaknesses of any kind were recorded as errors, while the positive features observed led to an appraisal of the development noticed across the tasks. All the errors in 200 scripts were recorded separately and sorted according to the error types. The errors were found to cluster around five classes i.e. mechanics, noun phrase, verb phrase, lexical items, and syntax (Bhattacharya 2001). 


\section{A STUDY OF WRITTEN ENGLISH IN NEPAL}

\section{RESULTS AND DISCUSSION}

Result: Science students outperformed.

Discussion: Among textbooks the Magic of Words has a section under exercises called Discussion Questions/ Writing Practice which is/are based on the contents of the texts. These questions require pupils to narrate events given in the story/poem/lesson which thus focuses on developing the ability in learners to organize that they have to communicate. Science students (Mean 3.88/0.74SD) were found the best in paragraph/creative writing, essay writing and story writing. Although the students of Management (3.18/0.70) held second position followed by Arts students (2.59/1.16), the performance of Management students is significantly better than the students of Arts and Education (2.13/0.81)but not significantly different from the students of Science stream and F-ratio/P-value is 38.28/0.000.

Result: Science students beat out their counterparts in writing.

Discussion: Science students wrote more number of sentences (2114) than the respondents of Management (1548), Arts (1198) and Education (1124). They wrote more number of correct sentences (1583/78.88\%) followed by learners of Management (933/60.27\%), Arts (680/56.76\%) and Education (362/32.21) respectively. But errors committed by students of Arts (1018) were less than the students of Management (1258) whereas Science students made 740 and Education 1694. The error per sentence was 0.35, 0.81, 0.85 and 1.51 of Science, Management, Arts and Education students respectively. The percentage of corrects words written was 97.54, 93.40, 93.00 and 87.75 by Science, Management, Arts and Education students respectively.

Result: Science students exceeded. Variations we are found in different area by different streams of students.

Discussion: Science students made maximum errors in syntax $(39.05 \%)$ followed by writing mechanics $(27.16 \%)$, noun phrase (12.30\%), lexical items (11.89\%) and verb phrase (9.59\%). Similarly, Students of Management also committed maximum errors in syntax $(37.36 \%)$ followed by writing mechanics (36.96\%), noun phrase (9.78\%), lexical items (9.70\%) and verb phrase (6.20\%). Likewise, students of Education committed more errors in syntax (36.84\%) followed by mechanics $(35.42 \%)$, lexical items $(21.13 \%)$, noun phrase $(5.73 \%)$ and verb phrase $(0.89 \%)$. But students of Arts had maximum errors in mechanics $(41.06 \%)$ followed by errors of syntax 
$(34.58 \%)$, lexical items $(11.49 \%)$, noun phrase $(7.56 \%)$ and verb phrase $(5.50 \%)$.

Teachers prefer essays (47.6\%) and paragraphs (38.1\%) writing. It is also strengthened by the students' responses that their writing is exam oriented and most of the examinations have questions that demand students to write essays/paragraphs. Paudyal's study (1999) also supports this finding that teaching exam-oriented writing is one of the major problem areas in writing.

Almost all the teachers and students responded that writing correct grammatical sentences is of utmost importance (54.5\%). Sixty-four percent teachers felt organising ideas is the most important in teaching English composition. It is also supported by students' responses. It is also one of the parameters for examining students' writing. Paudyal's (1999) study concludes that disorganization of ideas is also one of the major problem areas in writing.

Most of the topics $(86.3 \%)$ given to students for writing tasks are selected after discussion with the students. A large number of teachers believe that writing skill will assist in better language proficiency.

Some teachers say that the level of learning of English language is not adequate because of the students' emphasis on passing exam. Paudyal's (1999) study also supports the present finding that teaching exam-oriented writing is one of the major problem areas in writing.

Many of the teachers (59.1\%) after giving the feedback ask students to re-write. Students' responses also support this finding.

Most of the teachers (63.6\%) felt that there is lack of peer correction. Students' responses also support this finding. Nair's (1987) study also suggests that teachers relinquish their authority partly to peer-editing and partly self-editing by students.

Preposition, Tense, Reported Speech, Syntax, Relative Clause, Punctuation, Spelling, use of Causative Verbs and Complements are the most difficult grammatical areas for students. The studies of Pilla (1984), Sardana (1985), Nanjaih (1989), Sarma (1990), Paudyal (1999), Bhattarai (2002) and Karki (2012) also support it.

Result: Grammar teaching is crucial. 
Discussion: The demand to develop writing skill is high. Most of them (75\%) want that grammar should be taught in their writing classes. This finding is also supported by teachers' interview and the studies of Pilla (1984), Sardana (1985), Nanjaih (1989), Sarma (1990), Paudyal (1999), Bhattarai (2002) and Karki (2012).

Some of the students (24.2\%) can understand more than $75 \%$ content in their English period. Most of the students found that cocurricular activities are the most useful activities in the development of essay/paragraph writing competition.

Result: Process methodology is very popular.

Discussion: Almost all the teachers started the writing lesson by using process methodology.

All the teachers gave time to students to discuss the topic related to writing and did not exercise any control over students' thoughts and ideas and impose their own.

All of them discussed the students' grave mistakes in the classrooms without mentioning their names. Most of them did not give homework related to writing but all of them showed positive attitude towards writing and encourage students for regular reading and writing.

All of them emphasized paragraph and essay writing as these are very important from examination point of view.

All of them made students more active and performed the role of a facilitator.

\section{Modern ICT tools support to develop ignored but mostly demanded corrected written work.}

Discussion: All the teachers and the students expressed that writing is highly demanded skill but there is no separate class for it.

Most of the students do not pay due attention to their corrected written work as a result they repeat the same mistake.

No extra class in reality is conducted that has any bearing on writing. 
All the students have access to mobiles, internet, TVs which facilitate to develop their writing skill.

All the teachers follow marking scheme (Reading 40\%, Writing $40 \%$ and Grammar 20\%) provided by the board. They sometimes mark students' writings on their own set criteria.

All of them in a voice said that higher secondary school libraries lack relevant books to develop writing skill.

All the teachers unanimously said that higher secondary schools management committee was found promoting exam oriented teaching only.

Students' previous poor background creates a hindrance for the teachers to teach and correct writing related exercises.

All the teachers and students said that there should be regular reading writing practice. There was a good correlation among what informants said in interviews, what they wrote in response to the questionnaire and what the researcher observed in classroom teaching.

\section{MAJOR RECOMMENDATIONS}

One-third of the teachers believe that exercises in the lessons do not facilitate to develop writing skill so the book should be revised and such exercises should be replaced by practical and useful exercises/the new books.

To develop students' creativity and communication skills should be the prime focus of the teaching writing and such things should be disseminated through conducting workshop/seminar.

Visual aids should be used in the classroom to bring variety and remove monotony in the classroom.

Teaching of writing should not be only examination oriented but also useful in their daily life.

Students learn more and more from their peers. They do not hesitate to ask/show their weakness to their peers. So peer correction should be emphasized.

Extra classes should be arranged for those students who repeat mistakes after feedback. Some incentive should be provided to both teachers and students. 
Teachers should emphasize those grammatical items which cause the greatest difficulty to students. Students should be given more practice in those areas.

\section{ACKNOWLEDGMENTS}

I would like to thank Professor Neera Narang, Professor Umesh Kumar Mandal, and Professor Anjana Bhattarai who played pivotal role in advising me throughout the development of the larger study that served as the basis for this paper. I would also like to thank my colleague Madhu Neupane for providing relevant materials. Finally, thank you to the students who agreed to be participants in the study.

\section{REFERENCES}

Awasthi, J. R. (1995). A linguistic analysis of errors committed by Nepali learners of english. (Unpublished $\mathrm{PhD}$ dissertation). University of Hyderabad, Hyderabad, India.

Basnet, B. (2008). Proficiency of the students in guided writing. (Unpublished Master's dissertation). Tribhuvan University, Kathmandu, Nepal.

Begum, M. R. (2009). Effectiveness of communicative textbooks in english language teaching at secondary schools in Bangladesh. (Unpublished $\mathrm{PhD}$ dissertation). University of Rajshahi, Bangladesh.

Bhattacharya, T. N. (2001). Peer evaluation of 12 learners' writing as a pedagogical tool. (Unpublished M.Phil. dissertation). Central Institute of English and Foreign Languages, Hyderabad, India.

Bhatta, M. R. (2018). Inquiry based learning for developing writing skill. (Unpublished Master's dissertation). Tribhuvan University, Kathmandu, Nepal.

Bhattarai, P. P. (2002). A comparative study of the writing proficiency of the bachelor students. (Unpublished Master's dissertation). Tribhuvan University, Kathmandu, Nepal.

Bomer, R., Land, C. L., Rubin, J. C., \& Van Dike, L. M. (2019). Constructs of teaching writing in research about literacy teacher education. Journal of Literacy Research, 51(2): 196-213.

Coelho, R. (2020). Teaching writing in Brazilian public high schools. Reading and Writing, 33(6): 1477-1529. 
Dahal, K. (2011). Poor communities and livelihood in urban context: A case study of Kathmandu metropolitan city, Nepal.(Unpublished PhD thesis). University of Delhi, Delhi, India.

Gibbons, S. (2019). Death by PEEL? The teaching of writing in the secondary english classroom in England. English in Education, 53(1): 36-45.

Hairston, M., \& Keene, M. (2004). Successful writing. New York: W.W. Norton \& Company.

Harmer, J. (2006). How to teach writing. Delhi: Dorling Kindersley (India) Pvt. Ltd., licensees of Pearson Education in South Asia.

Karki, T. B. (2011). Developing writing proficiency through process writing. (Unpublished Master's Thesis). Tribhuvan University, Kathmandu, Nepal.

Limbu, S. (2020). Techniques used for providing feedback on students' writing. (Unpublished Master's Thesis), Tribhuvan University, Kathmandu, Nepal.

Lohani, S. P. \& Adhikari, R. P. (1999). The magic of words. Kathmandu: M. K. Publishers and Distributors.

Nair, P.B. (1987). A study of the writing component of the course in English at pre-degree level of the University of Calicut. (Unpublished M. Litt, Thesis). Central Institute of English and Foreign Languages, Hyderabad, India.

Nanjaih, R. (1989). A linguistic study of errors in the written english of PUC students with Kannada mother tongue. (Unpublished PhD dissertation). University of Mysore, Mysore, India.

Nirmala, Y. (2008). Teaching writing using picture stories and tools at the high school level: The movement from other regulation to self regulation. (Unpublished $M$. Phil. dissertation). The English and Foreign Languages University, Hyderabad, India.

Paudyal, H. L. (1999). A comparative study of english language writing of the students studying in higher secondary schools of Gulmi and Kathmandu district. (Unpublished Master's Thesis). Tribhuvan University, Kathmandu, Nepal.

Pilla, D. (1984). The CBSE class x course 'A' in English: An evaluation study of the writing curriculum. (Unpublished Master's Thesis). 
Central institute of English and Foreign Languages, Hyderabad, India.

Pokharel, S. (2019). Students' perceptions on the use of ICT in developing English language writing skills. (Unpublished master's. dissertation T.U., Kirtipur, Kathmandu.

Ramies, A. (1985). What skilled writers do as they write: Classroom study of composing. TESL Quarterly, 25(3): 407-430.

Sardana, K. A. (1985). An error analysis (written english) at the university stage. (Unpublished PhD dissertation). University of Delhi, Delhi, India.

Zanders. C. J., \& Wilson, E. (2019). Holistic, local, and process-oriented: What makes the university Utah's writing placement exam work. Assessing Writing, 41: 84-87.s 
Appendix I

GRADE POINT MEANS \& STANDARD DEVIATION (SD) FOR DIFFERENT STREAMS ON PARAGRAPH/CREATIVE WRITING, SHORT ESSAY WRITING AND SHORT STORY (PICTURE BASED) WRITING

Grade point means \& standard deviation across streams on total achievement

\begin{tabular}{llcccc}
\hline Streams & Medium & Mean & $\mathbf{n}$ & $\begin{array}{c}\text { Std. } \\
\text { Deviation }\end{array}$ & $\begin{array}{c}\text { Std. Error of } \\
\text { Mean }\end{array}$ \\
\hline Arts & English & 3.52 & 25 & 0.79977 & 0.15995 \\
& Nepali & 1.6533 & 25 & 0.53989 & 0.10798 \\
& Total & 2.5867 & 50 & 1.15972 & 0.16401 \\
\hline Managment & English & 3.3067 & 25 & 0.56862 & 0.11372 \\
& Nepali & 3.0533 & 25 & 0.79745 & 0.15949 \\
& Total & 3.18 & 50 & 0.69729 & 0.09861 \\
\hline Education & English & 1.8133 & 25 & 0.70106 & 0.14021 \\
& Nepali & 2.44 & 25 & 0.80346 & 0.16069 \\
& Total & 2.1267 & 50 & 0.81062 & 0.11464 \\
\hline Science & English & 3.8867 & 50 & 0.73651 & 0.10416 \\
& Total & 3.8867 & 50 & 0.73651 & 0.10416 \\
\hline
\end{tabular}

Means comparison among streams on total achievement

\begin{tabular}{|c|c|c|c|c|c|}
\hline \multirow[t]{2}{*}{ Streams } & \multirow{2}{*}{\multicolumn{2}{|c|}{$\mathbf{N}$}} & \multicolumn{3}{|c|}{$(1+2+3) / 3$} \\
\hline & & & \multicolumn{3}{|c|}{ All three's grade point Means(SD) } \\
\hline Arts & & 50 & \multicolumn{3}{|c|}{$2.5867(1.15972)$} \\
\hline Management & & 50 & \multicolumn{3}{|c|}{$3.18(0.69729)$} \\
\hline Education & & 50 & \multicolumn{3}{|c|}{$2.1267(0.81062)$} \\
\hline Science & & 50 & \multicolumn{3}{|c|}{$3.8867(0.73651)$} \\
\hline F- ratio/P-value & & & \multicolumn{3}{|c|}{$38.276 / 0.000$} \\
\hline \multicolumn{6}{|c|}{$\begin{array}{l}\text { Post Hoc test Significance values: Comparing Grade point } \\
\text { Means on total achievement across Streams }\end{array}$} \\
\hline Streams & Arts & & Management & Education & Science \\
\hline Arts & - & & 0.004 & 0.044 & $0.000^{\star *}$ \\
\hline Management & & & - & $0.000^{* *}$ & $0.000^{\star *}$ \\
\hline Education & & & & _- & $0.000^{\star *}$ \\
\hline Science & & & & & - \\
\hline
\end{tabular}




\section{Appendix II}

Stream/faculty wise learners' performance in the tests

\begin{tabular}{lcccc}
\hline Items & Science & Education & Arts & Management \\
\hline $\begin{array}{l}\text { 1. Total No. of Students } \\
\text { 2. Total No. of }\end{array}$ & 50 & 50 & 50 & 50 \\
$\quad \begin{array}{l}\text { Sentences Written } \\
\text { 3. Correct no. of }\end{array}$ & 1583 & 362 & 680 & 1548 \\
$\quad$ Sentences & & & & 933 \\
4. \% of Correct & 74.88174 & 32.2064057 & 56.76127 & 60.27132 \\
$\quad$ Sentences & & & & 1258 \\
5. Total Errors Made & 740 & 1694 & 1018 & 1258 \\
6. Error per Sentence & 0.350047 & 1.50711744 & 0.84975 & 0.812661 \\
7. Total Words & 30023 & 13825 & 14542 & 19066 \\
8. \% of Correct Words & 97.54 & 87.75 & 93.00 & 93.40 \\
\hline
\end{tabular}

Distribution of errors by stream/ faculty

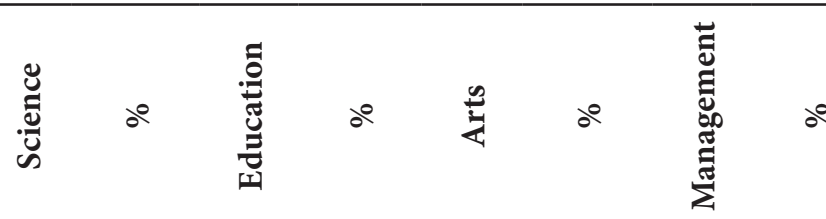

\begin{tabular}{lcccccccc}
\hline A. Mechanics & 201 & 27.16 & 600 & 35.42 & 418 & 41.06 & 465 & 36.96 \\
B. Noun Phrase & 91 & 12.30 & 97 & 5.73 & 77 & 7.56 & 123 & 9.78 \\
C. Verb Phrase & 71 & 9.59 & 15 & 0.89 & 56 & 5.50 & 78 & 6.20 \\
D. Lexical Item & 88 & 11.89 & 358 & 21.13 & 117 & 11.49 & 122 & 9.70 \\
E. Syntax & 289 & 39.05 & 624 & 36.84 & 352 & 34.58 & 470 & 37.36 \\
\hline Grand Total & $\mathbf{7 4 0}$ & $\mathbf{1 0 0 . 0 0}$ & $\mathbf{1 6 9 4}$ & $\mathbf{1 0 0 . 0 0}$ & $\mathbf{1 0 1 8}$ & $\mathbf{1 0 0 . 0 0}$ & $\mathbf{1 2 5 8}$ & $\mathbf{1 0 0 . 0 0}$ \\
\hline
\end{tabular}

